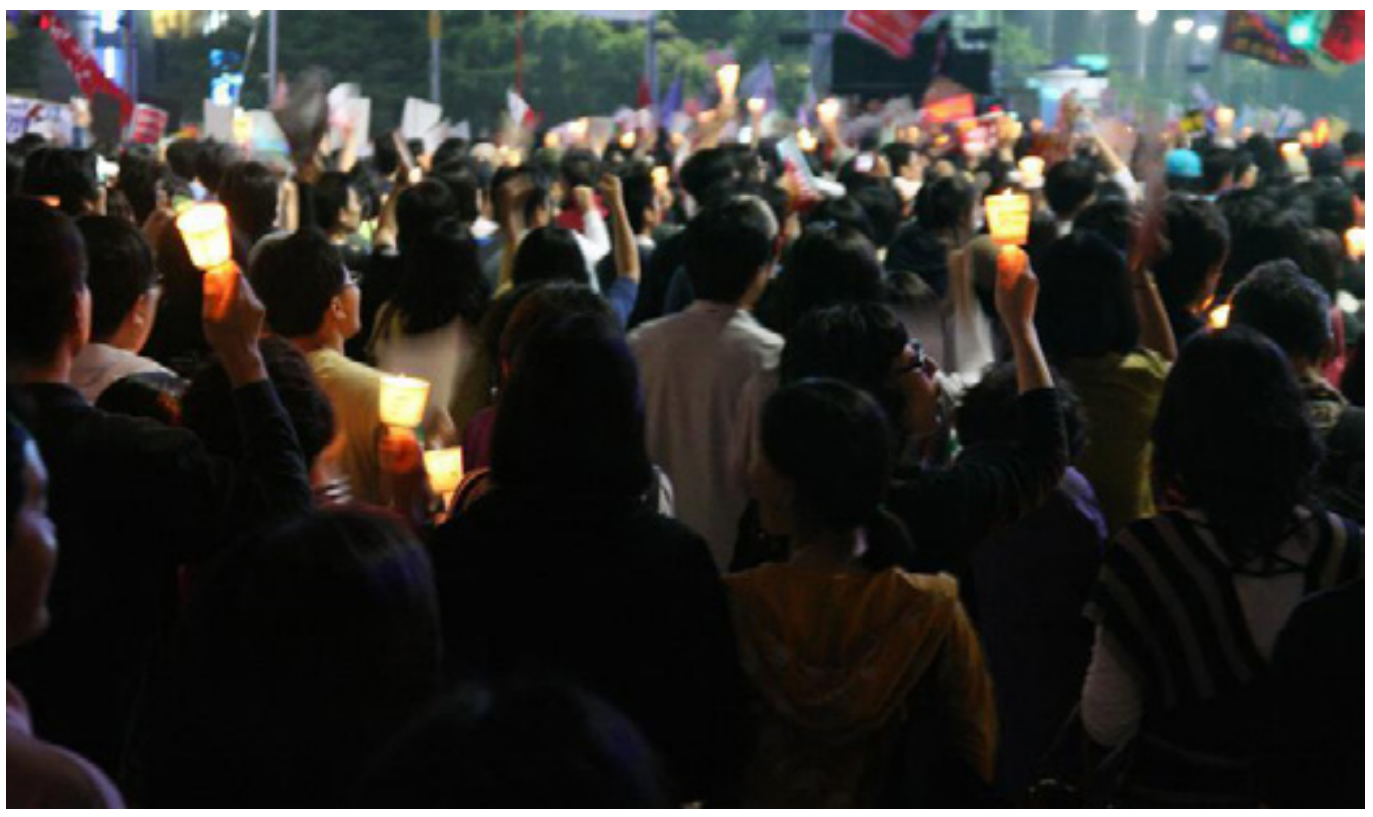

\section{Online Activism and South Korea's Candlelight Movement}

Hyejin Kim

The Candlelight Movement of 2016 and 2017 that successfully called for president Park Geun-hye to step down is among the largest social movements in South Korean history. This movement attracted millions of participants over a sustained period of time, while maintaining strikingly peaceful demonstrations that ultimately achieved their goal. This essay looks at the role of the Internet and new media in fostering a new generation of activists and laying the foundation for a successful social mobilisation.
Candlelight rally in Seoul, June 2008. PC: Michael-kay Park @flickr.com.

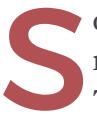
outh Korea has a storied history of mass agitation for political causes. The Candlelight Movement of 20162017, which called for president Park Geun-hye to step down, is among the largest-if not the largest-street demonstration in that history. Set against any of several measuring sticks, it was a remarkable success. It attracted millions of participants over a sustained period of time. The events were strikingly peaceful-strangers smashed up against each other and encountered police, but participants prevented violence and there was not a single fatality. And, of course, the National Assembly eventually impeached 
the president, who was later dismissed, tried in criminal court, and eventually sentenced to a lengthy prison term.

Globally, examples like South Korea's are rare in the present moment. At a time when 'populist' forces appear adept at mobilising discontent, and when political interests are capable of using the Internet to distort public discussion, there may be something to learn from South Korea. In fact, while the Candlelight Movement was a response to revelations that Park had been discharging her duties irresponsibly and allowing a personal associate to share inappropriately in her public power, its success hinged on more than the egregiousness of the wrongdoing.

\section{Cold War Legacies}

Demonstrations have long been a regular feature of life in Seoul. Aggrieved groups take quickly to the streets. While demonstrations indicate a liberal environment in which people are free to organise and express themselves, most have not ignited public support in the way the Candlelight Movement did. Divisions among activists have also plagued these events. The largest movements have seen divisions emerge between the unaffiliated individuals who initiated the action via online platforms and the established civil society groups.

Consider an episode from 2002, an especially significant year for mass political expression in South Korea, with a presidential election and fervent celebration of the nation around the hosting of the football World Cup. That year, individuals communicating over the Internet organised a candlelight vigil to commemorate two schoolgirls who had been killed in an incident involving American soldiers. As the peaceful movement progressed, some 130 civil society organisations joined in and raised other issues. Many of these groups chanted anti-American slogans, which expressed the frustration of many at Bush-era policies, but also alienated others who had been raised in a context where such views were taboo. Surveys show that individual participation declined when these organisations entered the fray (Kim 2008, 30).

Another set of candlelight vigils took place in 2008, this time in response to perceptions that the government was careless in relaxing restrictions on the import of American beef. These demonstrations also caused tension between online activists and established civil society groups. The movement was initiated by young people who organised themselves online (Kang 2017). The youth organisers had requested participating groups not to display banners at rallies, so that the protests would stay focussed on the particular issues at stake. However, civil society groups ignored these requests, and some even displayed a very militant attitude. In one instance, members carried steel pipes to protect themselves in the event of a police encounter, or perhaps to warn off the police. These civil society groups deliberately adopted the styles of authoritarianera anti-government activists. Participants who came prepared for confrontation contributed, in combination with the police response, to the outbreak of scuffles.

Images of militant-looking participants and of physical confrontations made it all too easy for the media to depict the 2008 candlelight protesters as disloyal activists. The figure of the violent, treasonous protester was a trope of Cold War politics in South Korea. The victims of military violence at Gwangju in 1980 were depicted in this way. The authoritarian regime had made a habit of hiring young men to initiate violence at opposition rallies, in order to perpetuate the view of critics as unpatriotic troublemakers. In 2008, these themes emerged again. Police confrontations at the demonstrations led to a downturn in the participation of individual citizens (Kim $2008,24)$. In the end, despite the fact that these demonstrations were organised by a new generation of online activists employing a completely different approach to their 
predecessors, conservative media portrayed participants in the 2008 candlelight vigils as communist sympathisers (Shin 2016).

The foundation of the divisions among activists lies in the Cold War legacies that continue to shape South Korea's civil society. While younger activists tend to form new, often issue-specific communities through the Internet, former activists of the 1970s and 1980s remain influential in organised civil society. The latter tend to use dramatic words like 'struggle' (tujaeng) to describe their activities and to use songs associated with the anti-dictatorship movement, as if they were still fighting against an authoritarian regime. Furthermore, in the early 2000s, conservatives revived McCarthyist language to discredit progressives, claiming they are pro-Pyongyang and seek to undermine the Republic of Korea. These depictions and the approach of some civil society groups could be off-putting to many middle-class Koreans who had assimilated anti-communist sentiments through political socialisation, even if they took positions favourable to redistributive policies. These political formations have driven a wedge between online-based activists focussed on particular causes and the realm of organised civil society.

\section{Podcasts and Spoons}

In the Candlelight Movement of 201617, however, these two groups managed to cooperate. Demands were formulated in a way that did not appear radical, which made the cause appealing to middle-class Koreans. Two new developments behind this achievement deserve attention.

First, critical discussion of politics had moved to online platforms over the previous decade. Under the Lee Myung-bak (2008-13) and Park Geun-hye (2013-17) administrations, South Korea experienced a number of setbacks in terms of political liberties. Many journalists and reporters who tackled issues that were sensitive to these presidents had to leave their positions or were demoted. These journalists and producers chose online outlets as spaces for continuing their work. In places where the government exerts strict controls on the media, the Internet can be an important tool for people to disclose injustice, as research on China has shown (Svensson 2016). In the South Korean context, this turn to online platforms did little to diminish the standing and credibility of these new media organisations. The Internet is where most people in South Korea go to get their news. According to the Reuters Journalism Research Centre at Oxford University, 77 percent of Korean news readers access media content through an Internet portal website, compared to an average in other countries closer to 30 percent (Newman et al 2017, 126).

As critical journalists left for online media, citizens followed. This led to a radical transformation of the media landscape in South Korea, with the emergence not only of new outlets but also of new formats. For instance, political podcasts have now become a form of online media that has grown in prominence over the past several years. Online media figures are extremely successful in pulling in listeners. Political programmes gain larger audiences than other traditional formats. The main platform, Podbbang, hosts 10,000 audio podcasts alone. Of their top 10 podcasts, seven address politics.

Second, online modes of political engagement were not only critical, but also entertaining. The most prominent podcasts are humorous and fun to tune into. Online platforms have produced entertaining ways of talking about politics. One example is a discourse around 'spoon theory' (sujeoron) (Kim 2017), which describes people born with or without privileges, respectively, as 'gold spoon' and 'dirt spoon'. Collectively, these were the most searched terms of 2015 on South Korean online portals (Choe 2015). Actors and singers whose parents were also celebrities were among the first to be labelled 'gold spoons'-they were criticised for making their way through their 


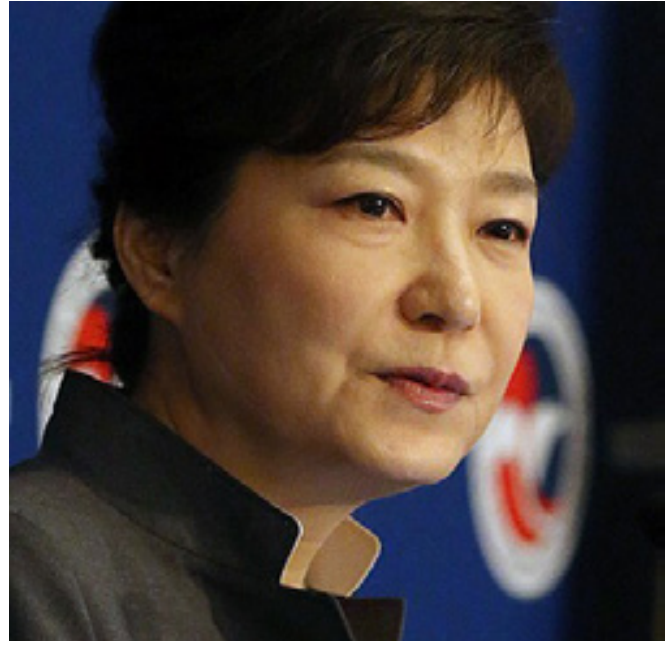

Former South Korean president Park Geun-hye. PC: Wikimedia Commons

parents' connections rather than through talent or hard work. Netizens then continued to show their creativity and make up distinct grades of privilege, such as 'diamond spoon' or 'platinum spoon'.

The 'spoon' terminology was a way to engage with the serious issue of wealth inequality. Related memes were shared for fun but they were also a means for society to learn about inequality and express concern about the issue. Other jokey discourses operated in a similar way. By presenting serious political themes in an entertaining light, the new modes of communication drew in audiences and gave these discussions a contemporary feel. In podcasts, the approach was to be overtly irreverent but at the same time hosts brought in experts and ensured that the conversation maintained substance. The style of the discussions resonates with a global Internet culture in which nothing is sacred and anything can be lampooned. Unlike previous instances of social mobilisation, spreading jokes about 'spoons' or watching someone laugh and curse the president simply does not fit with the images expected of 'pro-North Korean' forces. This style is far removed from what could be identified by conservatives as a radical-and therefore illegitimate-movement.

\section{Rediscovering the Internet as a Progressive Force}

By autumn 2016, when the Park scandal broke, many Koreans were already adept at thinking critically about the presidentespecially about inherited privilege, which Park, as the daughter of former dictator Park Chung-hee, represented. Ordinary Koreans were prepared to take to the streets against the sort of injustice that the scandal exposed.

These factors helped lay the groundwork for a movement that could overcome the Cold War categories that had undermined previous social mobilisations in South Korea. Now, more than a year after a new government was formed, public debates have moved in a progressive direction. The Justice Party, a labour party, became the second largest party in the National Assembly and has punched above its weight in setting policy discussions. Progressive issues such as the length of the working week, worklife balance, and women's status top both the political agenda and public debate. The ruling party finds itself under pressure from the Justice Party to take a progressive policy line.

There is hope to be found in the South Korean story. Mass political engagement can come in forms other than 'populist' support for anti-immigrant or racist causes. And, the Internet can also be a force for genuine political expression rather than a medium for distortion and manipulation. These points should be welcome in today's global political landscape. 